to the Bill \& Melinda Gates Foundation (BMGF). BMGF had no involvement in this publication.

Statement of Interest: Statements of interest for K. Steingart, A. Ramsay and M. Pai can be found at www.erj.ersjournals.com/ site/misc/statements.xhtml

Acknowledgements: We are very grateful to the more than $50 \mathrm{~TB}$ experts who completed our surveys or provided input. We remain responsible for any errors.

\section{REFERENCES}

1 Small PM, Pai M. Tuberculosis diagnosis - time for a game change. N Engl J Med 2010; 363: 1070-1071.

2 Pai M. Improving TB diagnosis: difference between knowing the path and walking the path. Expert Rev Mol Diagn 2011; 11: 241-244.

3 World Health Organization. Roadmap for Rolling Out Xpert MTB/RIF for Rapid Diagnosis of TB and MDR-TB. Geneva, World Health Organization, 2010.

4 Specter M. A Deadly Misdiagnosis. Why Millions of People Still Die from TB? New Yorker. November 15, 2010.

5 Morris K. WHO recommends against inaccurate tuberculosis tests. Lancet 2011; 377: 113-114.

6 Steingart KR, Henry M, Laal S, et al. A systematic review of commercial serological antibody detection tests for the diagnosis of extra-pulmonary tuberculosis. Thorax 2007; 62: 911-918.

7 Steingart KR, Henry M, Laal S, et al. Commercial serological antibody detection tests for the diagnosis of pulmonary tuberculosis: a systematic review. PLoS Med 2007; 4: e202.
8 World Health Organization. Diagnostics Evaluation Series No.2. Laboratory-Based Evaluation of 19 Commercially Available Rapid Diagnostic Tests for Tuberculosis. Geneva, World Health Organization, 2008.

9 Hopewell PC, Pai M, Maher D, et al. International standards for tuberculosis care. Lancet Infect Dis 2006; 6: 710-725.

10 Steingart KR, Flores L, Dendukuri N, et al. Commercial serological tests for the diagnosis of active pulmonary and extrapulmonary tuberculosis: an updated systematic review and meta-analysis. PLoS Med 2011; 8: e1001062.

11 World Health Organization. Commercial serodiagnostic tests for diagnosis of tuberculosis: policy statement. http:/ / whqlibdoc.who. int/publications/2011/9789241502054_eng.pdf Date last accessed: November 4, 2011. Date last updated: 21 July 2011.

12 Mudur GS. India alert against TB blood tests. www.telegraphindia. com/1110721/jsp/nation/story_14268228.jsp Date last accessed: November 4, 2011. Date last updated: July 21, 2011.

13 Mascarehnas A. Scientists warn against blood tests for TB, say inaccurate. www.expressindia.com/latest-news/Scientists-warn-againstblood-tests-for-TB-say-inaccurate/837274/ Date last accessed: November 4, 2011. Date last updated: August 26, 2011.

14 Pai M, Dowdy D, Steingart KR. Medical, public health and economic consequences of bad diagnostics for tuberculosis. http://blogs.plos. org/speakingofmedicine/2011/08/09/medical-public-health-andeconomic-consequences-of-bad-diagnostics-for-tuberculosis/ Date last accessed: November 4, 2011. Date last updated: August 9, 2011.

15 Chinnock P. The Scandal of TB Misdiagnosis. www.tropika.net/ svc/news/20101113/Chinnock-20101113-News-TB-India Date last accessed: November 4, 2011. Date last updated: November 13, 2010.

DOI: 10.1183/09031936.00070611

\title{
Palliative percutaneous cryoablation in a patient with locally advanced invasive thymoma
}

\section{To the Editors:}

Percutaneous cryoablation is considered to be a minimally invasive option for local treatment of cancer [1-3]. Its efficacy is now being documented in many organs, including the prostate, liver, kidney and lung. The goal of ablation procedures is typically complete local tumour control when surgical resection is not indicated, but ablation procedures, such as cryoablation, may also be applicable to the palliative care of cancer patients. Here, we present a case in which percutaneous cryoablation was considered to have contributed to symptom relief in a patient with unresectable, locally advanced, invasive thymoma of the mediastinum. To our knowledge, this is the first report of a needle ablation procedure performed for a mediastinal tumour.

A 29-yr-old female presented with intermittent cough that had existed for 2 yrs and had gradually worsened. An abnormal shadow on chest radiography was identified at another clinic and the patient was referred to our hospital (Division of General Thoracic Surgery, Dept of Surgery, School of Medicine, Keio University, Tokyo, Japan) in July 2004. At that time, she complained of frequent cough and dyspnoea. She could not lay flat on her back. Biopsy through parasternal mediastinotomy $[4,5]$ was performed, from which the pathological diagnosis was thymoma, type B3, according to the World Health Organization classification. The tumour was considered to be unresectable because it had encased the major vessels and the airway in the mediastinum (fig. 1a-c). Two courses of carboplatin plus VP-16 with concurrent radiation (total $50 \mathrm{~Gy}$ ) [6] were administered. Radiologically, no apparent changes were seen, but her cough and dyspnoea were worse 1 month after chemoradiotherapy. Facial oedema had also appeared. We speculated that progressive compression of the trachea, carina and superior vena cava by the tumour was, at least in part, responsible for these symptoms. Since chemoradiotherapy appeared to be ineffective at this point, we decided to attempt tumour volume reduction by cryoablation, primarily to reduce airway compression. In November 2004, percutaneous cryoablation was performed. The cryoablation protocol had been approved by the institutional review board in October 2002. Written consent was obtained from the patient.

The percutaneous cryoablation procedure was performed under local anaesthesia as previously described [1]. Under a multidetector row computed tomography $(\mathrm{CT})$ scanner with multislice CT fluoroscopy functions (Aquilion 64; Toshiba Med. Co. Ltd, Tokyo, Japan), using an outer insertion sheath, a 1.7-mm diameter cryoprobe (CRYOcare Cryosurgical Unit; Endocare, Irvine, CA, 

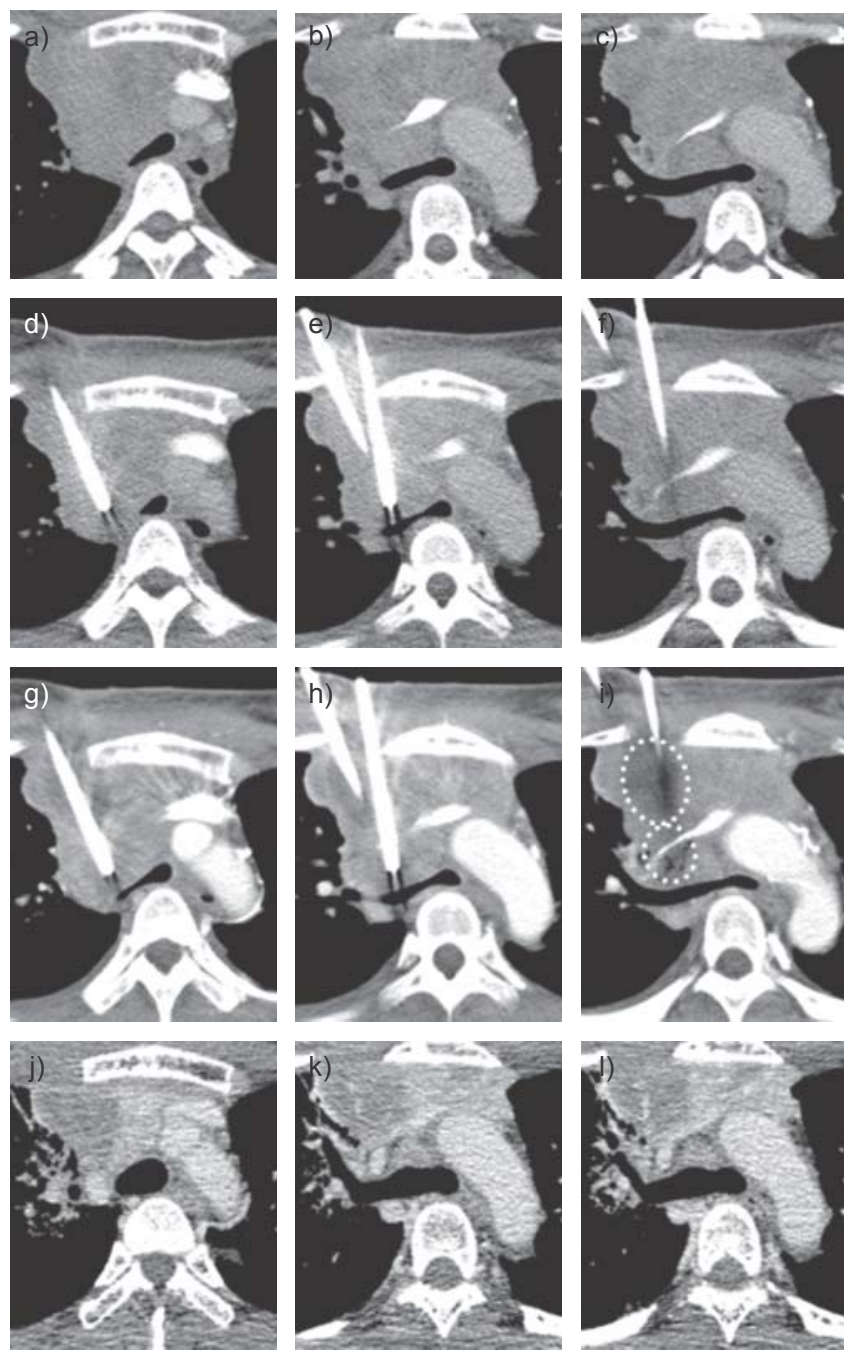

FIGURE 1. a-c) Computed tomography (CT) images showing a tumour in mediastinum compressing the trachea and the carina. The superior vena cava is not identified. d-f) CT images showing placement of two cryoprobes into the tumour in the vicinity of the airway. Care was taken to avoid puncturing the left innominate vein. $\mathrm{g}-\mathrm{i}) \mathrm{CT}$ images showing the cryoablated regions in the tumour immediately after cryoablation (dotted circles). j-l) CT images showing the ablated tumour 1 month after the cryoablation. The cryoablated region could be seen as a region with reduced contrast enhancement in the tumour. The tumour size was reduced and the airway compression was attenuated. Each set of three images represents axial CT slices $\sim 2 \mathrm{~mm}$ apart, depicting the extent of the tumour.

USA) was inserted into the tumour under fluoroscopic CT guidance. Two cryoprobes were inserted for the treatment of the tumour (fig. $1 \mathrm{~d}-\mathrm{f}$ ). Since the right side of the trachea, the carina and the right main bronchus appeared to be predominantly compressed, these regions of the tumour were targeted. Contrast enhancement was performed intermittently to image the major vessels, particularly to avoid damage to left innominate vein. The superior vena cava was considered to be obstructed and could not be identified. The cryoprobe uses high-pressure argon and helium gases for freezing and thawing, respectively, based on the Joule-Thompson principle. Cryoablation consisted of two 5-min cycles of freezing. The tip of the cryoprobe reached approximately $-130^{\circ} \mathrm{C}$ during freezing, followed by thawing until the temperature of the cryoprobe reached $20^{\circ} \mathrm{C}$, then a third cycle of freezing $(10 \mathrm{~min})$, followed by thawing. After the thawing, the cryoablated region of the tumour could be approximated as lowdensity areas in the tumour on CT (fig. 1g-i). The extent of the cryoablated region was considered to be sufficient for the purpose of this treatment and the outer insertion sheaths were removed. A whole-lung CT scan was performed at the end of the procedure. Chest radiographs were also checked after $2 \mathrm{~h}$, the next day and the day after each of the procedures. The $\mathrm{CT}$ and chest radiographs showed no evidence of complications, such as haemothoraces, pneumothoraces or air embolisms.

The patient's symptoms gradually improved and were significantly relieved 2 weeks after cryoablation. Her cough stopped and she was able to lie flat on her back. Her facial oedema was also relieved. On the CT scan taken 1 month after cryoablation, the cryoablated region could be seen as a region with reduced contrast enhancement in the tumour. The airway compression was attenuated and the tumour size was also reduced from 5.5 to $3.5 \mathrm{~cm}$ in greatest axial diameter (fig. $1 \mathrm{j}-1)$. Additional treatment was refused by the patient. The quality of life of the patient was satisfactory until she died of lung metastases in April 2008, 41 months after cryoablation.

Ablation procedures, particularly radio-frequency ablation, have been increasingly applied to cancers in many organs, including primary lung cancers and metastatic lung tumours. However, the feasibility of radio-frequency ablation for tumours in the lung hilum or the mediastinum are controversial, because it could cause vessel as well as airway injuries. Since 2002, we have performed percutaneous cryoablation of lung tumours as part of a clinical study in $>200$ patients at our institution without major vessel or airway injuries [1]. Additionally, cryoablation is known to preserve the collagenous architectures [7] and, hence, the integrity of the large vessels and airways [8]. Therefore, we considered that mediastinal lesions existing in the vicinity of major vessels or airways could be safely ablated by cryoablation.

In the present case, cryoablation was performed safely without any complications. During needle placement, care was taken to avoid direct puncture of the major vessels and airways. As for the local control of the tumour, we need to mention that not only cryoablation, but also the latent effects of the initial chemoradiotherapy, may have resulted in the symptom relief and size reduction of the tumour. However, we consider that cryoablation, at least in part, contributed to the symptom relief because her symptoms, which had been worsening, were relieved significantly after cryoablation.

In this case, cryoablation of a mediastinal tumour was feasible. Although further studies are necessary, percutaneous cryoablation may be an option in a multimodality treatment for the palliative control of locally advanced, treatment-refractory mediastinal tumours.

\section{Y. Yamauchi*, Y. Izumi*, K. Hashimoto*, H. Yashiro\#,} M. Inoue ", S. Nakatsuka\#, M. Kawamura and H. Nomori* *Division of General Thoracic Surgery, Dept of Surgery, "Dept of Diagnostic Radiology, School of Medicine, Keio University, and "Dept of Surgery, Teikyo University School of Medicine, Tokyo, Japan. 
Correspondence: Y. Izumi, Division of General Thoracic Surgery, Dept of Surgery, School of Medicine, Keio University, 35 Shinanomachi, Shinjuku-ku, Tokyo 160-8582, Japan. E-mail: yotaroizumi@a2.keio.jp

Statement of Interest: None declared.

\section{REFERENCES}

1 Kawamura M, Izumi Y, Tsukada N, et al. Percutaneous cryoablation of small pulmonary malignant tumours under computed tomographic guidance with local anaesthesia for nonsurgical candidates. J Thorac Cardiovasc Surg 2006; 131: 1007-1013.

2 Wang H, Littrup PJ, Duan Y, et al. Thoracic masses treated with percutaneous cryotherapy: initial experience with more than 200 procedures. Radiology 2005; 235: 289-298.
3 Yamauchi Y, Kawamura M. [Cryoablation for metastatic lung tumour derived from colorectal cancer.] Gan To Kagaku Ryoho 2009; 36: 1259-1262.

4 Kirschner PA. Cervical mediastinoscopy. Chest Surg Clin N Am 1996; 6: 1-20.

5 Olak J. Parasternal mediastinotomy (Chamberlain procedure). Chest Surg Clin N Am 1996; 6: 31-40.

6 Kaira K, Watanabe R, Takise A, et al. [Thymic cancer effectively treated by combination chemotherapy of carboplatin and etoposide with concurrent radiotherapy.] Gan To Kagaku Ryoho 2005; 32: 1989-1992.

7 Littrup PJ, Mody A, Sparschu R, et al. Prostatic cryotherapy: ultrasonographic and pathologic correlation in the canine model. Urology 1994; 44: 175-183.

8 Maiwand MO. The role of cryosurgery in palliation of tracheobronchial carcinoma. Eur J Cardiothorac Surg 1999; 15: 764-768.

DOI: 10.1183/09031936.00072211 